\title{
EGU2020-545
}

https://doi.org/10.5194/egusphere-egu2020-545

EGU General Assembly 2020

(c) Author(s) 2021. This work is distributed under

the Creative Commons Attribution 4.0 License.

\section{Geoarchaeological and paleoenvironmental reconstruction of the Late Quaternary climate- environmental-human nexus in the Kurdistan region of Iraq}

\author{
Luca Forti ${ }^{1}$, Eleonora Regattieri ${ }^{2}$, Anna Maria Mercuri ${ }^{3}$, Ilaria Mazzini ${ }^{4}$, Andrea Pezzotta ${ }^{1}$, Assunta \\ Florenzano ${ }^{3}$, Cecilia Conati Barbaro ${ }^{5}$, Luca Peyronel ${ }^{6}$, Daniele Morandi Bonacossi ${ }^{7}$, and Andrea \\ Zerboni $^{1}$ \\ ${ }^{1}$ Dipartimento di Scienze della Terra "Ardito Desio", Università degli Studi di Milano, Milano, Italy (luca.forti@unimi.it) \\ ${ }^{2}$ Istituto di Geoscienze e Georisorse, Consiglio Nazionale delle Ricerche, Pisa, Italy \\ ${ }^{3}$ Dipartimento di Scienze della Vita, Università di Modena e Reggio Emilia, Modena, Italy \\ ${ }^{4}$ Istituto di Geologia e Geoingegneria, Consiglio Nazionale delle Ricerche, Monterotondo (RM), Italy \\ ${ }^{5}$ Dipartimento di Scienze dell'Antichità, Università di Roma La Sapienza, Roma, Italy \\ ${ }^{6}$ Dipartimento di Studi Letterari, Filologici e Linguistici, Università degli Studi di Milano, Milano, Italy \\ ${ }^{7}$ Dipartimento di Studi Umanistici e del Patrimonio Culturale, Università degli Studi di Udine, Udine,Italy
}

During the late Quaternary, Iraqi Kurdistan was the scenario of several fundamental humanrelated

events including the dispersion of Homo in Asia and Europe, the origin of agriculture, the beginning

of urbanization, and the formation of the first state entities. We present the initial results of a geoarchaeological investigation in this area, which aims to reconstruct a detailed framework of the relationship between climatic changes, landscape responses, human adaptation, and settlement distribution during the Late Quaternary. Paleoenvironmental and paleoclimatic data were collected

from two key areas: the territory of the Navkur and Faideh plains, in northern Kurdistan, and a portion

of the Erbil plain, in southern Kurdistan. In the two regions, the Land of Niniveh and MAIPE archaeological missions are operating. Remote sensing, GIS analyses, and geomorphological survey

are the tools used for the geomorphological reconstruction of ancient hydrology (fluvial pattern) and

the evolution of distinct landforms. Geochemical and geochronological analyses on speleothems from

the Zagros piedmont caves of same region provide information on Holocene climatic variability in the area. Whereas environmental settings and human land use are investigated on the basis of sedimentological, palynological, micropaleontological, and geochemical analyses of a fluviolacustrine sequences preliminary dated between 40 and 9 ka BP. The lacustrine sequence is 


\section{composed}

by clayey and silt-sandy sediments alternating calcareous and organic matter-rich layers.

Environmental and geomorphological data have been compared with archaeological information (mostly the chronological distribution of the archaeological sites) to interpret exploitation of natural

resources, the settlement dynamics and shift in land use. 